\title{
(-)-Epigallocatechin gallate but not chlorogenic acid suppresses EGF-stimulated migration of osteoblasts via attenuation of p38 MAPK activity
}

\author{
TETSU KAWABATA $^{1,2}$, TAKANOBU OTSUKA ${ }^{1}$, KAZUHIKO FUJITA $^{1,2}$, GO SAKAI $^{1,2}$, \\ RIE MATSUSHIMA-NISHIWAKI ${ }^{2}$, OSAMU KOZAWA ${ }^{2}$ and HARUHIKO TOKUDA ${ }^{2,3}$
}

${ }^{1}$ Department of Orthopedic Surgery, Nagoya City University Graduate School of Medical Sciences, Nagoya,
Aichi 467-8601; ${ }^{2}$ Department of Pharmacology, Gifu University Graduate School of Medicine, Gifu 501-1194;
${ }^{3}$ Department of Clinical Laboratory, National Center for Geriatrics and Gerontology, Obu, Aichi 474-8511, Japan

Received July 21, 2017; Accepted September 13, 2018

DOI: $10.3892 / \mathrm{ijmm} .2018 .3884$

\begin{abstract}
Phenolic compounds provide health benefits in humans. A previous study by our group has indicated that the epidermal growth factor (EGF)-induced migration of osteoblast-like MC3T3-E1 cells is mediated by the phosphorylation of p44/p42 mitogen-activated protein (MAPK), p38 MAPK, stress-activated protein kinase (SAPK)/c-Jun N-terminal kinase (JNK) and Akt, and that resveratrol, a major polyphenol in grape skin, suppresses the EGF-induced migration by attenuating Akt and SAPK/JNK activation. In the present study, the effects of chlorogenic acid, a major phenolic acid in coffee, and (-)-epigallocatechin gallate (EGCG), a major flavonoid in green tea, on the EGF-induced migration of MC3T3-E1 cells were investigated. EGCG significantly reduced the EGF-induced migration as evaluated by a Transwell migration assay and by a wound healing assay. However, chlorogenic acid failed to affect the EGF-induced migration. The phosphorylation of p38 MAPK induced by EGF was significantly suppressed by EGCG; however, the EGF-induced phosphorylation of p44/p42 MAP kinase, SAPK/JNK or Akt was not affected by EGCG. These results suggest that EGCG, but not chlorogenic acid, suppresses EGF-induced osteoblast migration through inhibiting p38 MAPK activation.
\end{abstract}

\section{Introduction}

Bone metabolism is rigorously controlled by two different functional cell types-osteoblasts and osteoclasts $(1,2)$. Osteoblasts

Correspondence to: Professor Osamu Kozawa, Department of Pharmacology, Gifu University Graduate School of Medicine, 1-1 Yanagido, Gifu 501-1194, Japan

E-mail: okozawa@gifu-u.ac.jp

Key words: chlorogenic acid, epigallocatechin gallate, epidermal growth factor, migration, osteoblast, $\mathrm{p} 38$ mitogen-activated protein kinase are responsible for bone formation and osteoclasts for bone resorption. Bone tissue continues to regenerate in a process known as 'bone remodeling'. The process of bone remodeling starts with osteoclastic bone resorption and osteoblasts subsequently migrate to the sites resorbed by osteoclasts, resulting in the stimulation of bone formation. The orchestrated coupling of osteoblasts and osteoclasts maintains the appropriate bone mass. Metabolic bone diseases, including osteoporosis, are caused by the impairment of bone remodeling. Accumulating evidence indicates that osteoblast migration is pivotal for numerous processes in physiological bone metabolism, including responses to mechanical loading $(1,3,4)$. In addition, it has been indicated that osteoblast migration is essential for processes associated with pathological conditions of the bone, including tumor metastasis and the repair of bone fracture (5). It is widely recognized that various humoral factors, including epidermal growth factor (EGF), have important roles in bone metabolism $(3,4,6)$. As for the effects of EGF on osteoblasts, EGF reportedly stimulates their proliferation but suppresses their differentiation (7-10). In addition, it has been indicated that EGF enhances osteoblast migration (11). The migration of mesenchymal progenitors was reported to be mediated via phosphatidylinositol-3 kinase (PI3K)/Akt and p38 mitogen-activated protein kinase (MAPK) through the EGF receptor, which is activated by an EGF ligand released from osteoblasts (12). Regarding the intracellular signaling associated with the EGF-induced migration of osteoblasts, a recent study by our group suggested that p44/p42 MAPK, p38 MAPK, stress-activated protein kinase (SAPK)/c-Jun $\mathrm{N}$-terminal kinase (JNK) and Akt function as positive regulators in osteoblast-like MC3T3-E1 cells (13).

It is generally established that natural polyphenols contained in beverages and foods are beneficial for human health through exerting anti-oxidative, anti-inflammatory and anti-tumor effects $(14,15)$. Regarding the effects of natural polyphenolic compounds, several epidemiological studies indicate that chlorogenic acid, a major phenolic compound in coffee, and (-)-epigallocatechin gallate (EGCG), a major polyphenol in green tea, has beneficial properties on human health (16-18). As for the potential benefit on bone tissue, it 
is known that green tea consumption in elderly individuals leads to an increase of bone mass, improves the bone mineral density and decreases the risk of fracture (19). Chlorogenic acid has been reported to cause an increase of mineralization in rat tibia and improves the mechanical properties of the femoral diaphysis (20). In addition, it has been indicated that chlorogenic acid suppresses osteoclastic bone resorption due to downregulation of receptor activator of nuclear factor- $\kappa \mathrm{B}-$ ligand and its downstream effects (21). However, EGCG was reported to promote osteoblastic bone formation and inhibit osteoclastic bone resorption $(19,22)$. However, the mechanisms underlying the effects of chlorogenic acid or EGCG on bone metabolism remain to be clarified.

In the present study, it was investigated whether chlorogenic acid or EGCG affect the EGF induced-migration of osteoblast-like MC3T3-E1 cells. It was demonstrated that not chlorogenic acid but EGCG reduces the EGF-induced migration of osteoblasts through the suppression of p38 MAPK.

\section{Materials and methods}

Materials. Chlorogenic acid and EGCG were obtained from Sigma-Aldrich (Merck KGaA, Darmstadt, Germany). EGF was purchased from R\&D Systems, Inc. (Minneapolis, MN, USA). Antibodies to phosphorylated p38 MAPK (cat. no. 4511), p38 MAPK (cat. no. 9212), phosphorylated p44/p42 MAPK (cat. no. 9101), p44/p42 MAPK (cat. no. 9102), phosphorylated SAPK/JNK (cat. no. 9251), SAPK/JNK (cat. no. 9252), phosphorylated Akt (cat. no. 9275) and Akt (cat. no. 9272) were purchased from Cell Signaling Technology, Inc. (Beverly, MA, USA). GAPDH antibodies (cat. no. sc-25778) were obtained from Santa Cruz Biotechnology, Inc. (Dallas, TX, USA). An ECL Western blotting detection system (cat. no. RPN2108) was obtained from GE Healthcare UK Ltd. (Little Chalfont, UK). Chlorogenic acid was dissolved in ethanol and EGCG was dissolved in dimethyl sulfoxide to prepare stock solutions. The maximum concentration of dimethyl sulfoxide or ethanol during incubations was $0.1 \%$, which did not affect the cell migration assay or the western blot analysis.

Cell culture. Cloned osteoblast-like MC3T3-E1 cells that have been derived from newborn mouse calvaria (23) were provided by Dr Masayoshi Kumegawa (Meikai University, Sakado, Japan), and maintained as previously described (24). In brief, the cells were cultured in $\alpha$-minimum essential medium $(\alpha-\mathrm{MEM})$ obtained from Sigma-Aldrich (Merck KGaA) containing $10 \%$ fetal bovine serum (FBS) obtained from Gibco (Thermo Fisher Scientific, Inc., Waltham, MA, USA) at $37^{\circ} \mathrm{C}$ in a humidified atmosphere of $5 \% \mathrm{CO}_{2} / 95 \%$ air. The cells were seeded into $90-\mathrm{mm}$ diameter dishes $\left(2 \times 10^{5}\right.$ cells/dish) in $\alpha$-MEM containing $10 \%$ FBS. After 5 days, the medium was replaced with $\alpha$-MEM containing $0.3 \%$ FBS. After $48 \mathrm{~h}$, the cells were subjected to western blot analysis initiated by the EGCG pretreatment. For the cell migration assay, the cells cultured in $\alpha$-MEM containing $10 \%$ FBS for 3 days were sub-cultured in $\alpha$-MEM containing $0.3 \%$ FBS for $6 \mathrm{~h}$, and were then used for the experiments.

Cell migration assay. A Transwell cell migration assay was performed as described previously (25) using Boyden cham- bers (polycarbonate membrane with $8-\mu \mathrm{m}$ pores; Transwell ${ }^{\circledR}$; Corning Costar Corp., Cambridge, MA, USA). In brief, the cultured cells were trypsinized and seeded onto the upper chamber at $1 \times 10^{5}$ cells/well in $\alpha$-MEM containing $0.3 \%$ FBS. EGF $(10 \mathrm{ng} / \mathrm{ml})$ was added to the lower chamber in $\alpha$-MEM containing $0.3 \% \mathrm{FBS}$ and the cells were incubated for $16 \mathrm{~h}$ at $37^{\circ} \mathrm{C}$. Subsequently, the cells on the upper surface of the membrane were mechanically removed. The migrated cells adherent to the lower side of the membrane were fixed with $4 \%$ paraformaldehyde for $10 \mathrm{~min}$ at room temperature, and stained with 1:1,000 of DAPI solution (Wako Pure Chemical Industries, Ltd., Osaka, Japan) with $0.1 \%$ bovine serum albumin in phosphate buffered saline for $10 \mathrm{~min}$ at room temperature. Images of the migrated cells were captured under the fluorescent microscope (BZ-9000; Keyence Co., Ltd., Tokyo, Japan) at a magnification of $\mathrm{x} 20$ and the cells were quantified by counting the stained cells in three randomly chosen fields. When indicated, the cells were pre-treated with chlorogenic acid or EGCG for $60 \mathrm{~min}$ at $37^{\circ} \mathrm{C}$.

For the wound-healing assay, the cultured cells were seeded at $1 \times 10^{5}$ cells/well into an Ibidi Culture-Insert 2 Well (Ibidi, Martinsried, Germany) with a 500- $\mu$ m margin from the side of the well and allowed to grow for $24 \mathrm{~h}$. After the culture insert had been removed, the cells were stimulated with $30 \mathrm{ng} / \mathrm{ml}$ EGF for $8 \mathrm{~h}$. Images of the cells were captured using an EOS Kiss X4 digital camera (Canon, Tokyo, Japan) connected to a CK40 culture microscope (Olympus Optical Co. Ltd., Tokyo, Japan) prior to EGF stimulation and after $8 \mathrm{~h}$. The area into which the cells migrated was measured using ImageJ software (version 1.48; National Institutes of Health, Bethesda, MD, USA).

Western blot analysis. The cultured cells were pre-treated with various doses of EGCG for $60 \mathrm{~min}$ and then stimulated with either $50 \mathrm{ng} / \mathrm{ml}$ EGF or vehicle in $1 \mathrm{ml} \alpha$-MEM containing $0.3 \%$ FBS for the indicated durations. The cells were then lysed, homogenized and sonicated in a lysis buffer containing $62.5 \mathrm{mM}$ Tris/ $\mathrm{HCl}, \mathrm{pH}$ 6.8, 2\% SDS, $50 \mathrm{mM}$ dithiothreitol and $10 \%$ glycerol. SDS-PAGE was performed by the method of Laemmli (26) in $10 \%$ polyacrylamide gels. The protein was fractionated and transferred onto an Immun-Blot polyvinylidene difluoride membrane (Bio-Rad Laboratories, Hercules, CA, USA). The membranes were blocked with $5 \%$ fat-free dry milk in Tris-buffered saline-Tween-20 (TBS-T; $20 \mathrm{mM}$ Tris/ $\mathrm{HCl}, \mathrm{pH} 7.6,137 \mathrm{mM} \mathrm{NaCl}, 0.1 \%$ Tween 20 ) for $1 \mathrm{~h}$ prior to incubation with the primary antibodies. Western blot analysis was performed as described previously (27) using antibodies to phosphorylated p38 MAPK, p38 MAPK, phosphorylated p44/p42 MAPK, p44/p42 MAPK, phosphorylated SAPK/JNK, SAPK/JNK, phosphorylated Akt, Akt and GAPDH as primary antibodies and peroxidase-labeled antibodies raised in goat against rabbit immunoglobulin G (cat. no. 5110-0336; KPL Inc., Gaithersburg, MD, USA) as secondary antibodies. The primary and secondary antibodies were diluted at 1:1,000 with 5\% fat-free dry milk in TBS-T, and incubated for $24 \mathrm{~h}$ at $4{ }^{\circ} \mathrm{C}$ and for $60 \mathrm{~min}$ at room temperature, respectively. The peroxidase activity on the polyvinylidene difluoride sheet was visualized by means of the ECL western blotting detection system and images were captured on X-ray film (Fujifilm, Tokyo, Japan). Densitometric analysis was performed using 

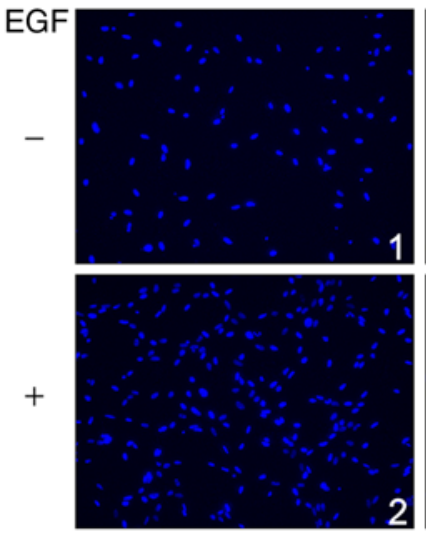

Chlorogenic acid $(\mu \mathrm{M}) \quad 0$
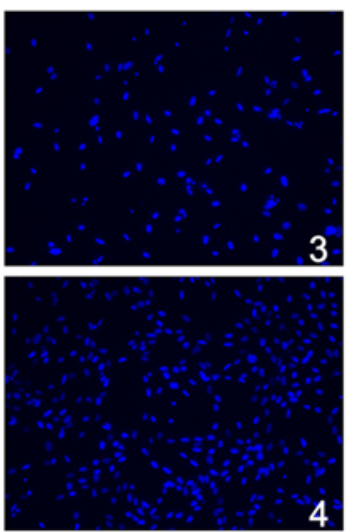

10
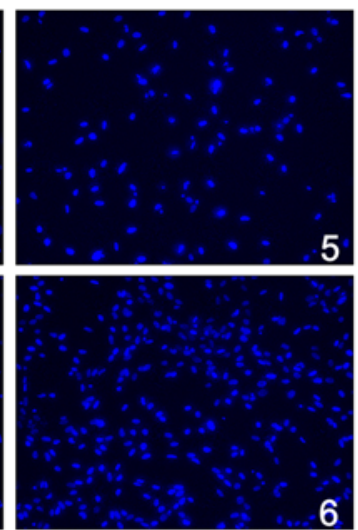

30
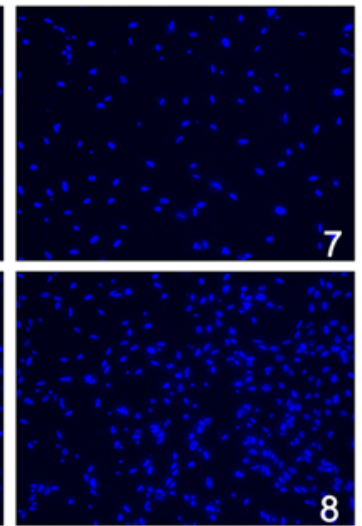

50

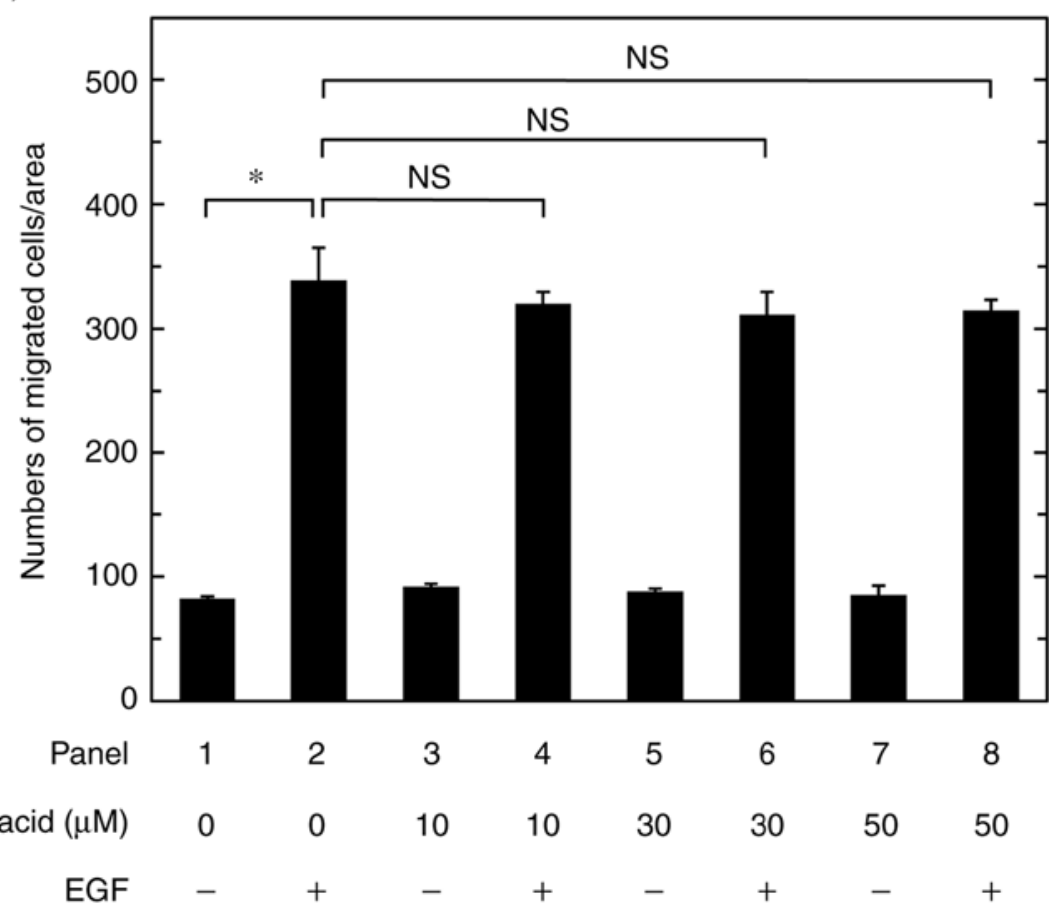

Figure 1. Effect of chlorogenic acid on the EGF-induced migration of MC3T3-E1 cells. The cell migration was examined by a Transwell assay. The cells were pre-treated with various doses of chlorogenic acid for $60 \mathrm{~min}$ and then stimulated by $10 \mathrm{ng} / \mathrm{ml}$ of EGF or vehicle for $16 \mathrm{~h}$. The migrated cells were fixed with paraformaldehyde and the nuclei were stained with DAPI (blue signal). Images of the migrated cells were captured by fluorescent microscopy at a magnification of $\times 20$ and the number of cells in each field was counted. Representative images and the histogram displaying the numbers of migrated cells in each group are presented. Values are expressed as the mean \pm standard error of the mean of triplicate determinations from three independent cell preparations. ${ }^{*} \mathrm{P}<0.05$ compared with the value of the control cells without EGF stimulation. NS, no significant difference between the indicated pairs; EGF, epidermal growth factor.

a scanner and image analysis software (ImageJ version 1.48). The phosphorylated protein levels were calculated as follows: The background-subtracted signal intensity of each phosphorylation signal was respectively normalized to the total protein signal and plotted as the fold increase in comparison to that of the control cells treated without stimulation.

Statistical analysis. The data were analyzed by analysis of variance followed by Bonferroni's method for multiple comparisons between pairs. $\mathrm{P}<0.05$ was considered to indicate a statistically significant difference. Microsoft Excel 2010 ver. 14.0 (Microsoft Corporation, Redmond, WA, USA) was used for the analysis. Values are expressed as the mean \pm standard error of the mean of triplicate determinations from three independent cell preparations.

\section{Results}

EGCG attenuates the EGF-induced migration of MC3T3-E1 cells. A recent study by our group has demonstrated that resveratrol suppresses the EGF-induced migration of osteoblast-like MC3T3-E1 cells by using a Transwell cell migration assay (13). In the present study, the effect of chlorogenic acid on EGF-induced migration in MC3T3-E1 cells was examined. However, chlorogenic acid at concentrations of up to $50 \mu \mathrm{M}$ did not affect the EGF-induced migration in the Transwell cell migration assay (Fig. 1).

Next, the effect of EGCG on the EGF-induced migration of MC3T3-E1 cells was examined. EGCG, which had little effect on the cell migration in the absence of EGF, significantly reduced the EGF-induced migration in the Transwell 

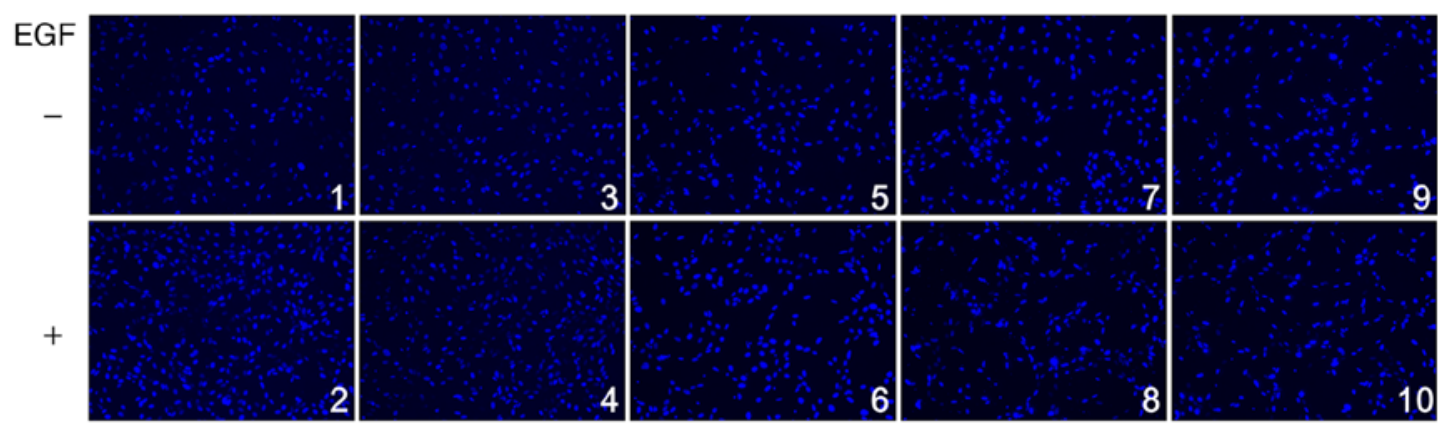

EGCG $(\mu \mathrm{M})$

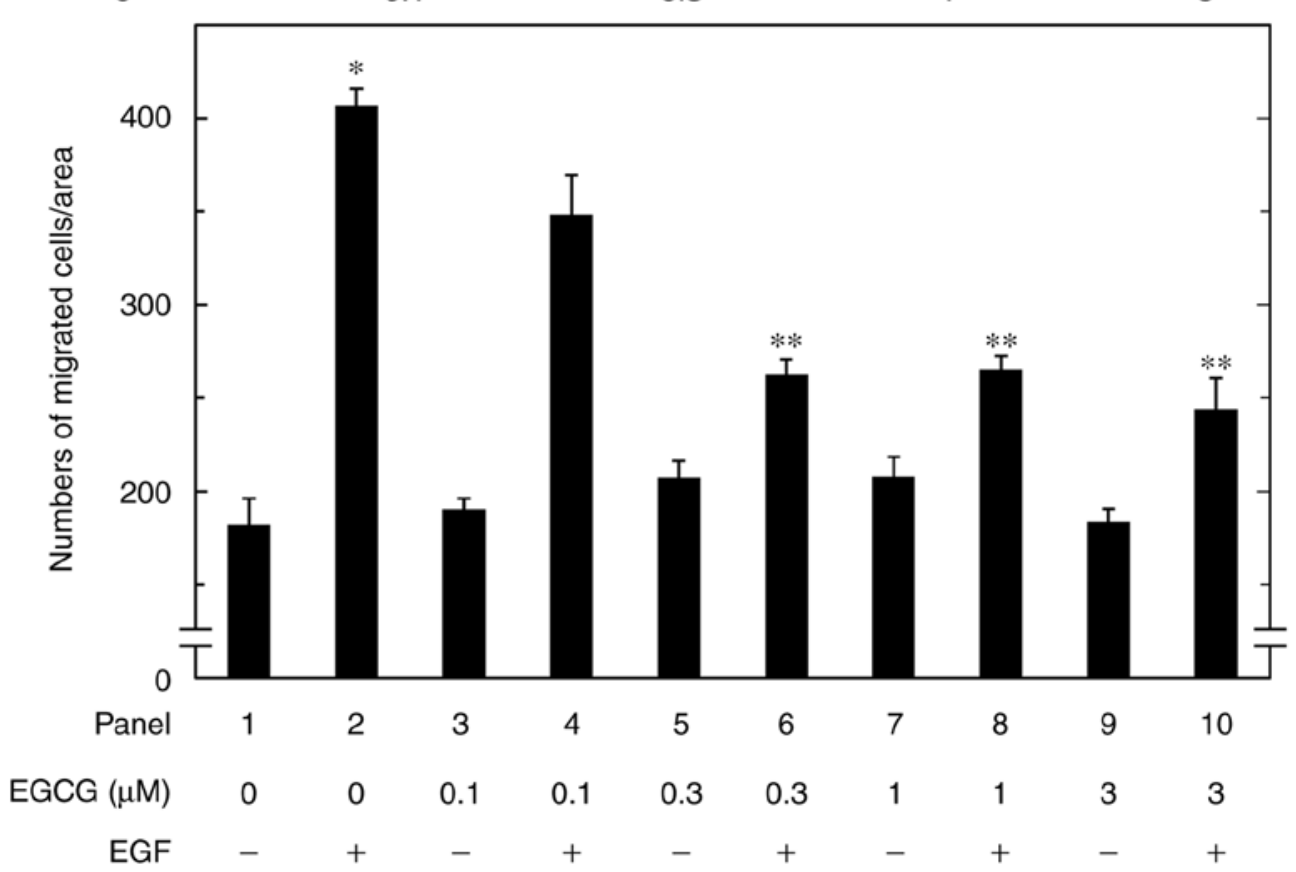

Figure 2. Effect of EGCG on EGF-induced migration of MC3T3-E1 cells. The cell migration was examined by a Transwell migration assay. The cells were pre-treated with various doses of EGCG for $60 \mathrm{~min}$ and then stimulated by $10 \mathrm{ng} / \mathrm{ml}$ of EGF or vehicle for $16 \mathrm{~h}$. The migrated cells were fixed with paraformaldehyde, and the nuclei were stained with DAPI (blue signal). Images of the migrated cells were captured by fluorescent microscopy at a magnification of x20 and the number of cells in each field was counted. Representative images and the histogram displaying the numbers of migrated cells in each group are presented. Values are expressed as the mean \pm standard error of the mean of triplicate determinations from three independent cell preparations. "P $<0.05$ compared with the value of the control cells without EGF stimulation. ${ }^{* *} \mathrm{P}<0.05$ compared with the value of EGF alone. EGF, epidermal growth factor; EGCG, (-)-epigallocatechin gallate.

cell migration assay (Fig. 2). The suppressive effect of EGCG on the cell migration was dose-dependent over the concentration range of 0.3-3.0 $\mu \mathrm{M}$. In addition, the wound-healing assay confirmed that the EGF-induced migration of osteoblast-like MC3T3-E1 cells was markedly attenuated by EGCG at $3 \mu \mathrm{M}$ (Fig. 3).

Effects of EGCG on the EGF-induced phosphorylation of p44/p42 MAPK, p38 MAPK, SAPK/JNK and Akt in MC3T3-E1 cells. A previous study by our group has demonstrated that the EGF-induced migration of osteoblast-like MC3T3-E1 cells proceeds via phosphorylation of p44/p42 MAPK, p38 MAPK, SAPK/JNK and Akt (13). In order to elucidate how EGCG suppresses the EGF-induced migration of osteoblast-like MC3T3-E1 cells, the effects of EGCG on the EGF-stimulated phosphorylation of p44/p42 MAPK, p38 MAPK, SAPK/JNK and Akt were examined. EGCG significantly attenuated the EGF-induced phosphorylation of p38 MAPK in MC3T3-E1 cells (Fig. 4). However, EGCG failed to affect the phosphory- lation of p44/p42 MAPK, SAPK/JNK and Akt in these cells (Figs. 5-7).

\section{Discussion}

In the present study, it was demonstrated that EGCG, a major constituent of green tea catechins, significantly suppressed EGF-stimulated migration of osteoblast-like MC3T3-E1 cells. The inhibitory effect of EGCG on the cell migration was significant even at $0.3 \mu \mathrm{M}$. Since it has been indicated that the plasma concentration of EGCG in humans reaches 0.1-0.3 $\mu \mathrm{M}$ after moderate green tea consumption (28), it is probable that the effect of EGCG on osteoblast migration is physiologically relevant for green tea drinkers. However, chlorogenic acid, a major polyphenol in coffee, had no effect on the EGF-stimulated cell migration in the present study. Next, the exact mechanism underlying the inhibition of EGF-stimulated osteoblast-like MC3T3-E1 cell migration by EGCG was investigated. With regard to the intracellular signaling of EGF in osteoblasts, it 

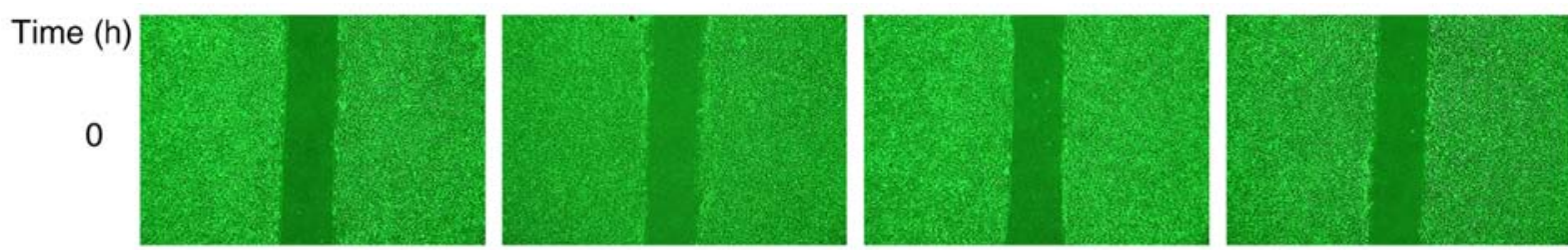

8
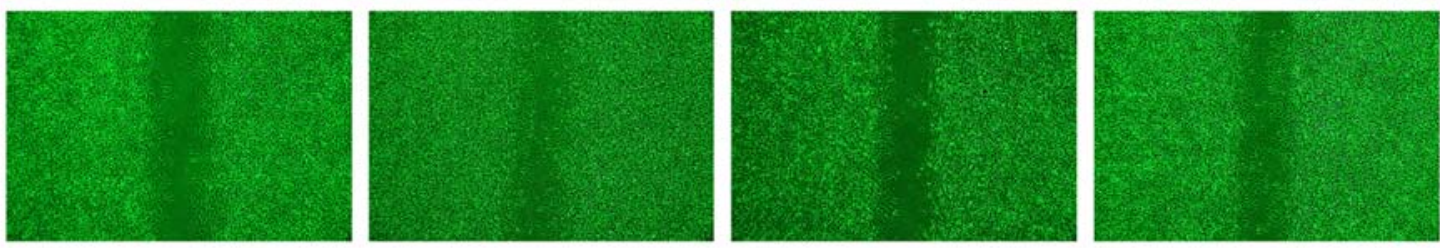

$E G C G$
$E G F$
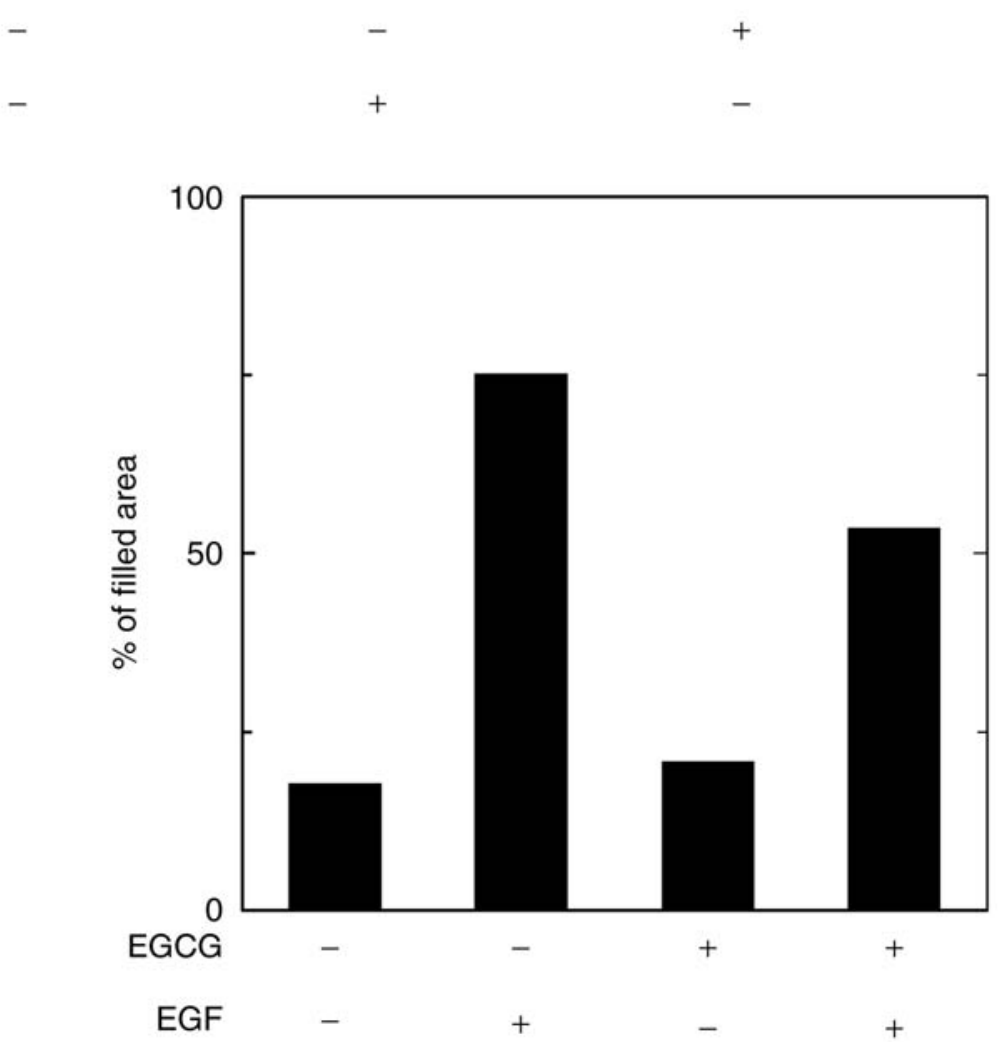

Figure 3. Effect of EGCG on the EGF-induced migration of MC3T3-E1 cells. The cell migration was examined by a wound-healing assay. The cells were seeded into an Ibidi Culture-Insert 2 Well with a 500- $\mu \mathrm{m}$ margin from the side of the well and allowed to grow for $24 \mathrm{~h}$. After the culture insert had been removed, the cells were pre-treated with $3 \mu \mathrm{M}$ EGCG or vehicle for $60 \mathrm{~min}$ and then stimulated by $30 \mathrm{ng} / \mathrm{ml}$ EGF or vehicle for another $8 \mathrm{~h}$. Images of the cells were captured prior to EGF stimulation $(0 \mathrm{~h}$ ) and after $8 \mathrm{~h}$ (upper panel), and the area of the migrated cells was measured (lower bar graph). EGF, epidermal growth factor; EGCG, (-)-epigallocatechin gallate.

has been reported that parathyroid hormone stimulates the release of amphiregulin, an EGF ligand, in osteoblasts. The released amphiregulin subsequently promotes the migration of mesenchymal progenitors due to activation of PI3K/Akt and p38 MAPK through binding to EGF receptor (12). A recent study by our group has indicated that the EGF-induced MC3T3-E1 cell migration is mediated at least partially through $\mathrm{p} 44 / \mathrm{p} 42$ MAPK, p38 MAPK, SAPK/JNK and Akt, but not p70 S6 kinase or Rho-kinase, suggesting that p44/p42 MAPK, p38 MAPK, SAPK/JNK and Akt act as mediators in the migration (13). In the present study, it was revealed that EGCG markedly reduced the EGF-induced phosphorylation of p38 MAPK in MC3T3-E1 cells. However, EGCG had little effect on the phosphorylation of p44/p42 MAPK, SAPK/JNK and Akt induced by EGF. Based on these results, it is most likely that EGCG inhibits
EGF-induced migration of osteoblast-like MC3T3-E1 cells by suppressing the phosphorylation of p38 MAPK.

Emerging evidence indicates that osteoblast migration to the sites resorbed by osteoclasts is pivotal not only for physiological bone metabolism, including skeletal development and bone remodeling, but also for processes associated with pathological conditions of the bone, including osteoporosis, bone fracture repair and tumor metastasis (3-5). An appropriate amount of migration of osteoblasts is required for the regulation of bone turnover, and such an adequate migration is considered to be essential for the maintenance of the quantity of bone mass as well as bone quality. Taking these points into account, it appears likely that EGCG modulates osteoblast migration, resulting in the regulation of adequate bone remodeling. 

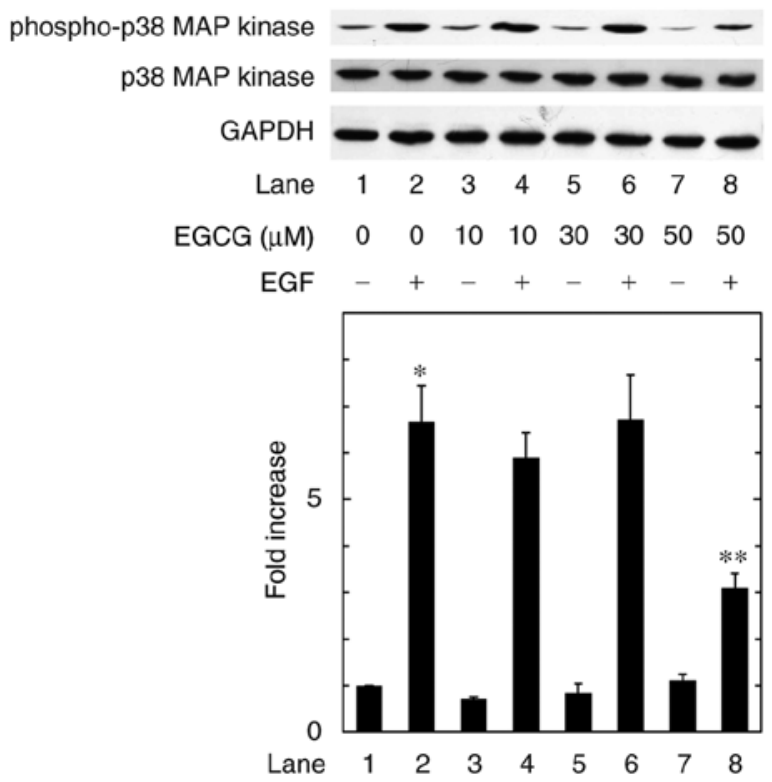

Figure 4. Effect of EGCG on the EGF-induced phosphorylation of p38 MAPK in MC3T3-E1 cells. The cultured cells were pre-treated with various doses of EGCG for $60 \mathrm{~min}$ and then stimulated by $50 \mathrm{ng} / \mathrm{ml}$ of EGF or vehicle for $10 \mathrm{~min}$. The protein extracts of the cells were then subjected to western blot analysis with antibodies against phosphorylated p38 MAPK, p38 MAPK or GAPDH. The histogram provides a quantitative representation of the levels of EGF-induced phosphorylation obtained from a laser densitometric analysis of three independent experiments. Values are expressed as the mean \pm standard error of the mean of triplicate determinations from three independent cell preparations. ${ }^{*} \mathrm{P}<0.05$ compared with the value for the control cells without EGF stimulation. ${ }^{* *} \mathrm{P}<0.05$ compared with the value for EGF alone. EGF, epidermal growth factor; EGCG, (-)-epigallocatechin gallate; MAPK, mitogen-activated protein kinase.

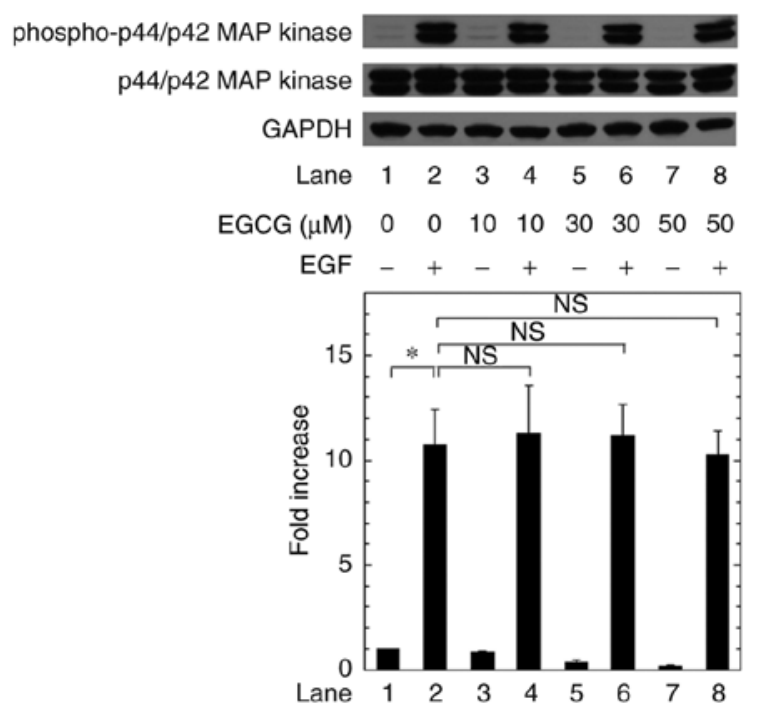

Figure 5. Effect of EGCG on the EGF-induced phosphorylation of p44/p42 MAPK in MC3T3-E1 cells. The cultured cells were pre-treated with various doses of EGCG for $60 \mathrm{~min}$ and then stimulated by $50 \mathrm{ng} / \mathrm{ml}$ of EGF or vehicle for $3 \mathrm{~min}$. The protein extracts of the cells were then subjected to western blot analysis with antibodies against phosphorylated p44/p42 MAPK, p44/p42 MAPK or GAPDH. The histogram provides a quantitative representation of the levels of EGF-induced phosphorylation obtained from a laser densitometric analysis of three independent experiments. Values are expressed as the mean \pm standard error of the mean of triplicate determinations from three independent cell preparations. ${ }^{*} \mathrm{P}<0.05$ compared with the value of the control cells without EGF stimulation. NS, no significant difference between the indicated pairs; EGF, epidermal growth factor; EGCG, (-)-epigallocatechin gallate; MAPK, mitogen-activated protein kinase.
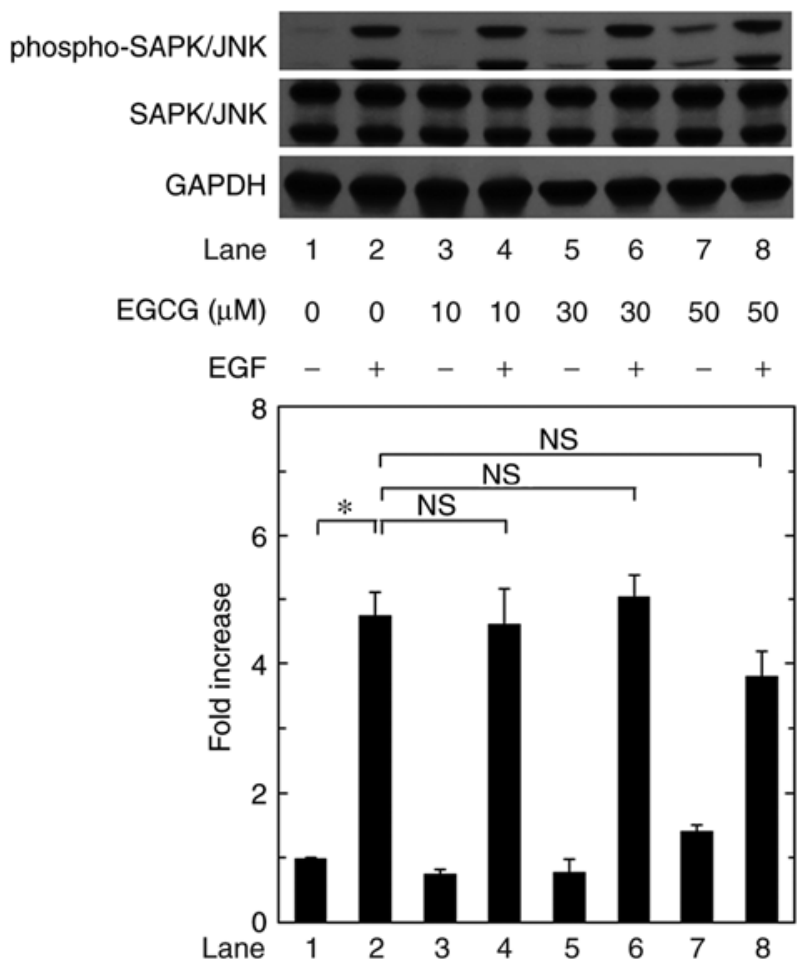

Figure 6. Effect of EGCG on the EGF-induced phosphorylation of SAPK/JNK in MC3T3-E1 cells. The cultured cells were pre-treated with various doses of EGCG for $60 \mathrm{~min}$ and then stimulated by $50 \mathrm{ng} / \mathrm{ml}$ of EGF or vehicle for $10 \mathrm{~min}$. The protein extracts of the cells were then subjected to western blot analysis with antibodies against phosphorylated SAPK/JNK, SAPK/JNK or GAPDH. The histogram provides a quantitative representation of the levels of EGF-induced phosphorylation obtained from a laser densitometric analysis of three independent experiments. Values are expressed as the mean \pm standard error of the mean of triplicate determinations from three independent cell preparations. " $\mathrm{P}<0.05$ compared with the value for the control cells without EGF stimulation. NS, no significant difference between the indicated pairs; EGF, epidermal growth factor; EGCG, (-)-epigallocatechin gallate; JNK, C-Jun N-terminal kinase; SAPK, stress-activated protein kinase.

EGCG is the most abundant catechin occurring in green tea $(17,19)$. It is currently recognized that green tea consumption leads to an increase of bone mass, improves the bone mineral density and decreases the risk of bone fracture (19). EGCG reportedly inhibits the migration of several malignant cell types, including skin cancer (29), prostate cancer (30) and pancreatic cancer cells (31). Regarding non-malignant cells, it has been indicated that EGCG suppresses endothelial cell migration (32). In addition, in alveolar bone cells, lower concentrations of EGCG (1,5 and $10 \mu \mathrm{M})$ alone reportedly have no effect on the migration, whereas higher concentrations of EGCG ( 25 and $50 \mu \mathrm{M}$ ) alone decrease the cell migration as revealed by a wound-healing assay (33). In the present study, a Transwell cell migration assay demonstrated that a lower concentration of EGCG, which had little effect on the cell migration in the absence of EGF, significantly reduced the EGF-induced migration of osteoblast-like MC3T3-E1 cells. The suppressive effect of EGCG was dose-dependent over the range of 0.3-3 $\mu \mathrm{M}$. Furthermore, EGCG at $3 \mu \mathrm{M}$ markedly suppressed the EGF-induced MC3T3-E1 cell migration in a wound-healing assay. The ability of EGCG to suppress EGF-induced osteoblast migration may be a mechanism of its beneficial effects on proper bone remodeling, which explains 

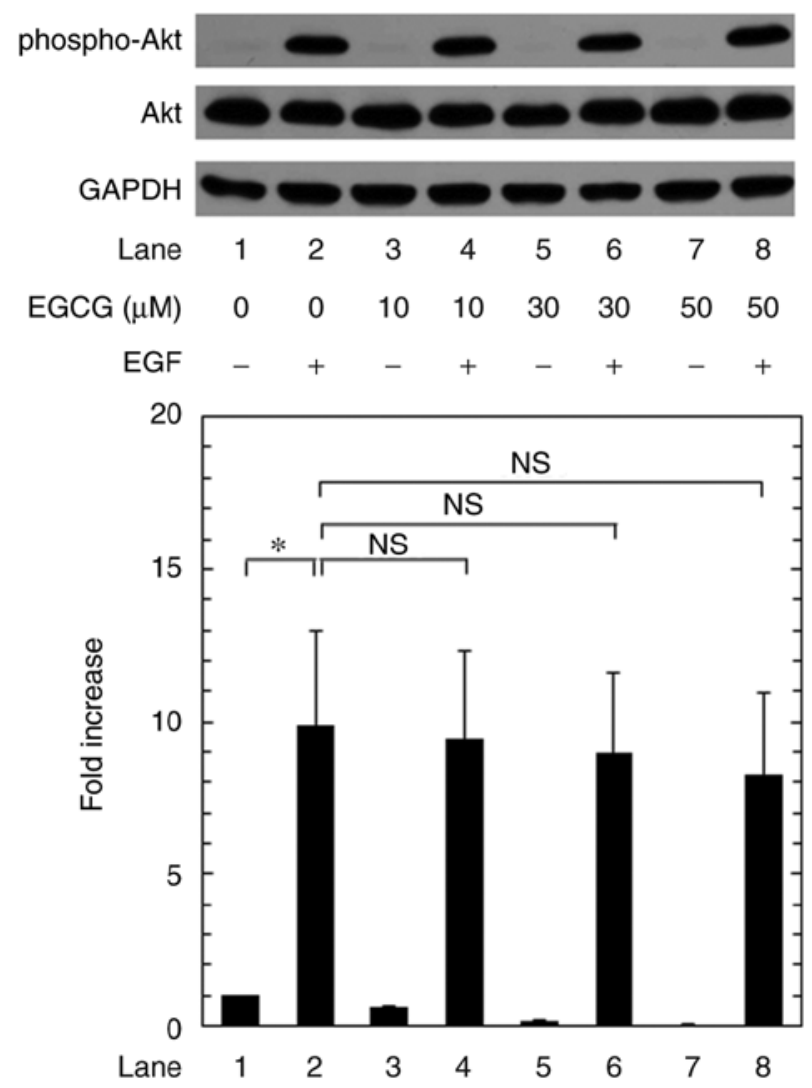

Figure 7. Effect of EGCG on the EGF-induced phosphorylation of Akt in MC3T3-E1 cells. The cultured cells were pre-treated with various doses of EGCG for $60 \mathrm{~min}$, and then stimulated by $50 \mathrm{ng} / \mathrm{ml}$ of EGF or vehicle for $3 \mathrm{~min}$. The protein extracts of the cells were then subjected to western blot analysis with antibodies against phosphorylated Akt, Akt or GAPDH. The histogram provides a quantitative representation of the levels of EGF-induced phosphorylation obtained from a laser densitometric analysis of three independent experiments. Values are expressed as the mean \pm standard error of the mean of triplicate determinations from three independent cell preparations. ${ }^{\text {"P }}<0.05$ compared with the value of the control cells without EGF stimulation. NS, no significant difference between the indicated pairs; EGF, epidermal growth factor; EGCG, (-)-epigallocatechin gallate.

for the favorable effects of EGCG on bone health. Further studies are in progress to elucidate the molecular mechanisms underlying the inhibitory effects of EGCG on EGF-induced migration of osteoblasts.

In conclusion, the results of the present study suggest that EGCG but not chlorogenic acid significantly reduces EGF-induced osteoblast migration and that the inhibitory effect of EGCG is exerted at least partially through the inhibition of p38 MAPK activation triggered by EGF.

\section{Acknowledgements}

The authors would like to thank Mrs. Yumiko Kurokawa (Department of Pharmacology, Gifu University Graduate School of Medicine, Gifu, Japan) for technical assistance.

\section{Funding}

This investigation was supported in part by Grants-in-Aid for Scientific Research from the Ministry of Education (grant no. 26462289 to OK and grant no. 15K10487 to HT), a Grant-in-Aid for Scientific Research from the Ministry of Health, Labor and Welfare (grant no. H25-Aging-General004 to HT), and the Research Funding for Longevity Sciences from the National Center for Geriatrics and Gerontology, Japan (grant nos. 25-4 and 26-12 to HT).

\section{Availability of data and materials}

The datasets used and/or analyzed during the current study are available from the corresponding author on reasonable request.

\section{Authors' contributions}

TK, TO and OK conceived and designed the experiments. TK, KF, GS and RMN performed the experiments. TK, KF, GS RMN, HT and OK analyzed the data. TK, TO, HT and OK wrote the manuscript. All authors read and approved the final manuscript.

\section{Ethics approval and consent to participate}

Not applicable.

\section{Patient consent for publication}

Not applicable.

\section{Competing interests}

The authors declare that they have no competing interests.

\section{References}

1. Karsenty G and Wangner EF: Reaching a genetic and molecular understanding of skeletal development. Dev Cell 2: 389-406, 2002.

2. Kular J, Tickner J, Chim SM and Xu J: An overview of the regulation of bone remodeling at cellular level. Clin Biochem 45: $863-873,2012$.

3. Khan SN, Bostrom MP and Lane JM: Bone growth factors. Orthop Clin North Am 31: 375-388, 2000.

4. Lieberman JR, Daluiski A and Einhorn TA: The role of growth factors in the repair of bone. Biology and clinical applications. J Bone Joint Surg Am 84-A: 1032-1044, 2002.

5. Reddi AH, Roodman D, Freeman C and Mohla S: Mechanisms of tumor metastasis to the bone: Challenges and opportunities. J Bone Miner Res 18: 190-194, 2003.

6. Schneider MR, Sibilia M and Erben RC: The EGFR network in bone biology and pathology. Trends Endocrinol Metab 20: 517-524, 2009.

7. Kumegawa M,Hiramatsu M,Hatakeyama K, Yajima T,Kodama H, Osaki T and Kurisu K: Effects of epidermal growth factor on osteoblastic cells in vitro. Calcif Tissue Int 35: 542-548, 1983.

8. Hata R, Hori H, Nagai Y, Tanaka S, Kondo M, Hiramatsu M, Utsumi $\mathrm{N}$ and Kumegawa M: Selective inhibition of type 1 collagen synthesis in osteoblastic cells by epidermal growth factor. Endocrinology 115: 867-876, 1984.

9. Ng KW, Partridge NC, Niall M and Martin TJ: Stimulation of DNA synthesis by epidermal growth factor in osteoblast-like cells. Calcif Tissue Int 35: 624-628, 1983.

10. Fang MA, Kujubu DA and Hahn TJ: The effects of prostaglandin $\mathrm{E}_{2}$, parathyroid hormone, and epidermal growth factor on mitogenesis, signaling, and primary response genes in UMR 106-01 osteoblast-like cells. Endocrinology 131: 2113-2119, 1992.

11. Vukicevic S, Kleinman HK, Luyten FP, Roche AB and Reddi AH: Identification of multiple active growth factors in basement membrane Matrigel suggests caution in interpretation of cellular activity related to extracellular matrix components. Exp Cell Res 202: 1-8, 1992. 
12. Zhu J, Siclari VA, Liu F, Spatz JM, Chandra A, Divieti Pajevic P and Qin L: Amphiregulin-EGFR signaling mediates the migration of bone marrow mesenchymal progenitors toward PTH-stimulated osteoblasts and osteocytes. PLoS One 7: e50099, 2012.

13. Kawabata T, Tokuda H, Fujita K, Kainuma S, Sakai G, Matsushima-Nishiwaki R, Kozawa O and Otsuka T: Resveratrol inhibits the epidermal growth factor-induced migration of osteoblasts: The suppression of SAPK/JNK and Akt. Cell Physiol Biochem 43: 1025-1036, 2017.

14. Jankun J, Selman SH, Wiercz RS and Skrzypczak-Jankun E: Why drinking green tea could prevent cancer. Nature 387: 561, 1997.

15. Koo SH and Montminy M: In vino veritas: A tale of two sirt1s. Cell 127: 1091-1093, 2006.

16. George SE, Ramalakshmi K and Mohan Rao LJ: A perception on health benefits of coffee. Crit Rev Food Sci Nutr 48: 464-486, 2008.

17. Thielecke $\mathrm{F}$ and Boschmann M: The potential role of green tea catechins in the prevention of the metabolic syndrome-a review. Phytochemistry 70: 11-24, 2009.

18. Shimizu M, Adachi S, Masuda M, Kozawa O and Moriwaki $\mathrm{H}$ Cancer chemoprevention with green tea catechins by targeting receptor tyrosine kinases. Mol Nutr Food Res 55: 832-843, 2011.

19. Shen CL, Yeh JK, Cao JJ and Wang JS: Green tea and bone metabolism. Nutr Res 29: 437-456, 2009.

20. Folwarczna J, Pytlik M, Zych M, Cegieła U, Nowinska B Kaczmarczyk-Sedlak I, Sliwinski L, Trzeciak H and Trzeciak HI: Effects of caffeic and chlorogenic acids on the rat skeletal system. Eur Rev Med Pharmacol Sci 19: 682-693, 2015.

21. Kwak SC, Lee C, Kim JY, Oh HM, So HS, Lee MS, Rho MC and $\mathrm{Oh} \mathrm{J:} \mathrm{Chlorogenic} \mathrm{acid} \mathrm{inhibits} \mathrm{osteoclast} \mathrm{differentiation}$ and bone resorption by down-regulation of receptor activator of nuclear factor kappaB ligand-induced nuclear factor of activated T cells c1 expression. Biol Pharm Bull 36: 1779-1786, 2013.

22. Singh R, Akhtar N and Haqqi TM: Green tea polyphenol epigallocatechin-3-gallate: Inflammation and arthritis. [Corrected] Life Sci 86: 907-918, 2010.

23. Sudo H, Kodama H, Amagai Y, Yamamoto $S$ and Kasai S: In vitro differentiation and calcification in a new clonal osteogenic cell line derived from newborn mouse calvaria. J Cell Biol 96: 191-198, 1983.

24. Kozawa O, Tokuda H, Miwa M, Kotoyori J and Oiso Y: Cross-talk regulation between cyclic AMP production and phosphoinositide hydrolysis induced by prostaglandin $\mathrm{E}_{2}$ in osteoblast-like cells. Exp Cell Res 198: 130-134, 1992.
25. Karagiosis SA, Chrisler WB, Bollinger N and Karin NJ: Lysophosphatidic acid-induced ERK activation and chemotaxis in MC3T3-E1 preosteoblasts are independent of EGF receptor transactivation. J Cell Physiol 219: 716-723, 2009.

26. Laemmli UK: Cleavage of structural proteins during the assembly of the head of bacteriophage T4. Nature 227: 680-685, 1970.

27. Kato $\mathrm{K}$, Ito $\mathrm{H}$, Hasegawa $\mathrm{K}$, Inaguma $\mathrm{Y}$, Kozawa $\mathrm{O}$ and Asano T: Modulation of the stress-induced synthesis of hsp27 and $\alpha \mathrm{B}$-crystallin by cyclic AMP in C6 rat glioma cells. J Neurochem 66: 946-950, 1996.

28. Yang CS, Chen LS, Lee ML, Balentine D, Kuo MC and Schantz SP: Blood and urine levels of tea catechins after ingestion of different amounts of green tea by human volunteers. Cancer Epidemiol Biomark Prev 7: 351-354, 1998.

29. Liu JS, Chen SH, Lin CL, Tsai SH and Liang YC: Inhibition of melanoma growth and metastasis by combination with (-)-epigallocatechin-3-gallate and dacarbazine in mice. J Cell Biochem 83: 631-642, 2001.

30. Siddiqui IA, Malik A, Adhami VM, Asim M, Hafeez BB, Sarfaraz S and Mukhtar H: Green tea polyphenolEGCG sensitizes human prostate carcinoma LNCaP cells to TRAIL-mediated apoptosis and synergistically inhibits biomarkers associated with angiogenesis and metastasis. Oncogene 27: 2055-2063, 2008.

31. Shankar S, Ganapathy S, Hingorani SR and Srivastava RK: EGCG inhibits growth, invasion, angiogenesis and metastasis of pancreatic cancer. Front Biosci 13: 440-452, 2008

32. Singh AK, Seth P, Anthony P, Husain MM, Madhavan S, Mukhtar H and Maheshwari RK: Green tea constituent epigallocatechin-3-gallate inhibits angiogenic differentiation of human endothelial cells. Arch Biochem Biophys 401: 29-37, 2002.

33. Mah YJ, Song JS, Kim SO, Lee JH, Jeon M, Jung UW, Moon SJ, Kim JH and Choi HJ: The effect of epigallocatechin-3-gallate (EGCG) on human alveolar bone cells both in vitro and in vivo. Arch Oral Biol 59: 539-549, 2014.

(i) $\Theta$ This work is licensed under a Creative Commons Attribution-NonCommercial-NoDerivatives 4.0 International (CC BY-NC-ND 4.0) License. 